\title{
EDITORIAL
}

\section{Support nurses and midwives to strengthen healthcare systems}

\author{
AUTHORS \\ Bronwyn Fields ${ }^{1} \mathrm{PhD}$, Assistant Professor * \\ Bongi Sibanda ${ }^{2}$ DNPc, MSc, ANP, RN, FHEA, Chief Nursing Officer/Advanced Practice Educator
}

Ian Couper ${ }^{3}$ MFamMed, FCFP(SA), Professor and Director, icouper@sun.ac.za

\section{CORRESPONDENCE}

*A/Prof Bronwyn Fields bronwyn.fields@csus.edu

\section{AFFILIATIONS}

${ }^{1}$ School of Nursing, California State University, Sacramento, CA 95669, USA

${ }^{2}$ APN Africa, Zimbabwe/UK

${ }^{3}$ Ukwanda Centre for Rural Health, Faculty of Medicine and Health Sciences, Stellenbosch University, South Africa

\section{PUBLISHED}

13 June 2020 Volume 20 Issue 2

\section{HISTORY}

RECEIVED: 13 May 2020

REVISED: 30 May 2020

ACCEPTED: 31 May 2020

\section{CITATION}

Fields B, Sibanda B, Couper I. Support nurses and midwives to strengthen healthcare systems. Rural and Remote Health 2020; $20: 6110$. https://doi.org/10.22605/RRH6110

\section{ETHICS APPROVAL}

NA

This work is licensed under a Creative Commons Attribution 4.0 International Licence

\section{FULL ARTICLE:}

Nurses and midwives make up more than half of the global health workforce ${ }^{\mathbf{1}}$. WHO has designated 2020 as the Year of the Nurse and Midwife ${ }^{2}$ to recognize their contribution, and to highlight the challenges they face in meeting the needs of the communities they serve. Both the International Council of Nurses' International
Nurses Day ${ }^{3}$ and the first State of the World's Nursing report ${ }^{4}$, recently launched by the International Council of Nurses and WHO respectively, highlight the crucial role played by nurses and midwives in health promotion, disease prevention and treatment. Their role is even more important in Africa, and in low- and 
middle-income countries (LMICs) in other regions, where nurses are often the only health professionals accessible to rural and remote communities.

The article '"Being a midwife is being prepared to help women in very difficult conditions": midwives' experiences of working in the rural and fragile settings of Ituri Province, Democratic Republic of Congo' $\mathbf{5}$ identifies specific work challenges faced by midwives in a rural part of Africa plagued by conflict and crisis, including shortages of qualified health workers, shortages of equipment and supplies, and lack of professional support. The article also identifies coping strategies used by midwives in Ituri, including lobbying local organizations for supplies, training others to provide essential care, and supporting their families through farming or other work when their government salaries are not paid.

These themes resonate around the world as we face the COVID-19 pandemic. Nurse and midwives in all countries (high, middle and low income) and in all areas (rural and urban) are facing similar challenges. They are facing shortages of equipment and supplies, particularly personal protective equipment. They are dealing with health worker shortages, as nurses and others fall sick, and as hospitals and clinics are overwhelmed by increased demand for services. They are challenged by a lack of professional support as they are asked to work without sufficient personal protective equipment, and to provide care they may not feel adequately trained or prepared to deliver ${ }^{\mathbf{6}}$. These themes are also reflected in the State of the World's Nursing report ${ }^{\mathbf{4}}$, and by International Nurses' Day ${ }^{3}$. There is a global nursing shortage of almost 9 million ${ }^{7}$, a lack of nursing faculty to absorb the number of nursing applicants, and poor remuneration and recruitment for nurses in many countries. Again, LMICs are the worst affected, with many African countries having alarming nurse/midwife-topopulation ratios ${ }^{3}$, largely due to migration of nurses to highincome countries for better salaries and careers ${ }^{\mathbf{8}}$. In addition to member states adhering to the WHO Global Code of Practice on international recruitment of health personnel ${ }^{\mathbf{9}}$ to help retain workforce, significant investment must be made in health workforce planning, education and retention ${ }^{\mathbf{1 0}}$. Introducing advanced practice nursing and midwifery roles, using relevant labor market approaches, and modernizing nursing education, are critical to achieving universal health coverage.

Yet nurses and midwives around the world are stepping up to face
COVID-19, despite the challenges, demonstrating the same coping strategies used by the midwives in Ituri. They are lobbying their local organizations and governments for supplies, they are 'leaning in' and volunteering to support other nurses in areas that are hardest hit by the pandemic. Professional nursing organizations are writing to local, state and national leaders to demand that nurses be provided with the supplies, equipment and professional support they need to protect their patients, themselves and their communities from the COVID-19 virus. Nurse educators, alongside other health professionals, are re-training nurses and midwives as their scope of work expands beyond their usual duties. Local community members are donating resources and time in a demonstration of their trust and support for nurses and other health workers. Mainstream media, and rural and remote health specific blogs, have chronicled the challenges health workers are facing, and have ignited broad recognition and support.

Nurses are supporting each other, and their communities, despite the personal risk. They are demonstrating their commitment to their patients and their profession. This is what nurses and midwives do - during civil wars, during disasters, during pandemics. This is what nurses and midwives do - in countries as diverse as the Democratic Republic of Congo, the USA and the UK. However, nurses and midwives cannot tackle these health challenges alone. Overcoming the present and future health challenges will require that nurses and midwives are supported as members of interprofessional teams that are well led and well integrated to bridge the gap between primary and secondary care. Such interprofessional collaboration can bring about positive changes in health care ${ }^{\mathbf{1 1}}$. Family nurse practitioners and family physicians can play a critical role in building health systems, and providing effective leadership and supervision for primary care teams in rural and remote communities. Health ministries in Africa need to commit to the training and deployment of family physicians to enable them to support interprofessional primary healthcare teams, where there has historically been a shortage of expertise $^{\mathbf{1 2}}$.

One of the most important lessons of the COVID-19 pandemic is surely the need to strengthen healthcare systems, in all contexts and even more in rural areas, not just in Africa but everywhere ${ }^{\mathbf{1 3}}$. Scaling up training and support of nurses and midwives as crucial members of interprofessional teams, especially in primary care and pandemic preparedness, are essential elements in these efforts.

\section{REFERENCES:}

1 Ajuebor O, McCarthy C, Li Y, Al-Blooshi SM, Makhanya N, Cometto G. Are the Global Strategic Directions for Strengthening Nursing and Midwifery 2016-2020 being implemented in countries? Findings from a cross-sectional analysis. Human Resources for Health 2019; 17: 54. https://doi.org/10.1186 /s12960-019-0392-2 PMid:31300058

2 World Health Organization. Year of the nurse and midwife 2020. 2020. Available: https://www.who.int/news-room/campaigns/yearof-the-nurse-and-the-midwife-2020 (Accessed 12 April 2020).
3 International Council of Nurses. Nursing the world to health. 2020. Available: https://www.icn.ch/what-we-docampaigns /international-nurses-day (Accessed 12 April 2020).

4 World Health Organization. State of the World's Nursing 2020: investing in education, jobs and leadership. Geneva: World Health Organization, 2020.

5 Baba A, Theobald S, Martineau T, Sabuni P, Nobabo MM, Alitimango A. 'Being a midwife is being prepared to help women in very difficult conditions': midwives' experiences of working in the 
rural and fragile settings of Ituri Province, Democratic Republic of Congo. Rural and Remote Health 2020; 20: 5677. Available: https://www.rrh.org.au/journal/article/5677 (Accessed 12 April 2020).

6 International Council of Nurses and International Red Cross/Red Crescent. International Nurses Day: nurses deserve praise, thanks, protection amid COVID-19. 2020. Available: https://www.icn.ch /sites/default/files/inline-

files/PR_22_NursesDayjointNR2020_Final_0.pdf (Accessed 1 May 2020).

7 Drennan VM, Ross F. Global nurse shortages - the facts, the impact and action for change. British Medical Bulletin 2019; 130(1): 25-37. https://doi.org/10.1093/bmb/ldz014 PMid:31086957

8 Salami B, Dada FO, Adelakun FE. Human resources for health challenges in Nigeria and nurse migration. Policy, Politics, \& Nursing Practice 2016; 17(2): 76-84. https://doi.org/10.1177 /1527154416656942 PMid:27365339

9 World Health Organization. WHO Code of Practice on International Recruitment of Health Personnel (WHA63. 16). 2010.

Available: https://www.who.int/hrh/migration /code/code_en.pdf?ua=1 (Accessed 17 April 2020).

10 Couper I, Worley P. The ethics of international recruitment. Rural and Remote Health 2002; 2: 196. Available: http://www.rrh.org.au/journal/article/196 (Accessed 25 May 2020).

11 Zwarenstein M, Goldman J, Reeves S. Interprofessional collaboration: effects of practice-based interventions on professional practice and healthcare outcomes. Cochrane Database of Systematic Reviews 2009; 3: CD000072. https://doi.org/10.1002 /14651858.CD000072.pub2

12 Flinkenflögel M, Sethlare V, Cubaka VK, Makasa M, Guyse A, De Maeseneer J. A scoping review on family medicine in sub-Saharan Africa: practice, positioning and impact in African health care systems. Human Resources for Health 2020; 18(1): 27. https://doi.org/10.1186/s12960-020-0455-4 PMid:32245501

13 Worley P. Why we need better rural and remote health, now more than ever. Rural and Remote Health 2020; 20: 5976. Available: http://www.rrh.org.au/journal/article/5976. https://doi.org/10.22605/RRH5976 PMid:32204597 (Accessed 25 May 2020).

This PDF has been produced for your convenience. Always refer to the live site https://www.rrh.org.au/journal/article/6110 for the Version of Record. 